\title{
Diagnostic testing for Prader-Willi syndrome and Angelman syndrome: A cost comparison
}

\author{
Kristin G. Monaghan, PhD, Anne Wiktor, and Daniel L. Van Dyke, PhD
}

\begin{abstract}
Purpose: Considering cost as a factor, the authors evaluated three approaches to the diagnostic testing of Prader-Willi syndrome (PWS) and Angelman syndrome (AS). Methods: The approaches evaluated were (1) DNA methylation studies followed by fluorescence in situ hybridization (FISH) for any positive DNA result, (2) FISH analysis followed by DNA testing for any negative result, and (3) simultaneous DNA testing and FISH analysis. Results: Of 136 samples submitted for chromosome analysis and DNA methylation analysis for PWS or AS, 114 had a normal chromosome analysis and methylation studies, 9 were positive for AS, 3 were positive for PWS, and $7 \mathrm{had}$ an abnormal chromosome analysis, but not deletion 15q11.2-q13, and normal methylation studies. On the basis of these results, the authors compared the cost of each testing strategy. Conclusion: DNA methylation studies followed by confirmation with FISH for any positive result yields a significant cost savings compared with the other approaches. Genet Med 2002:4(6):448-450.
\end{abstract}

Key Words: Prader-Willi syndrome, Angelman syndrome, cost analysis

Prader-Willi syndrome (PWS) is characterized by hypotonia and failure to thrive in the newborn period. Obesity generally begins after the onset of hyperphagia, often between the ages of 1 to 6 years. Individuals with PWS have mild to moderate mental retardation, small hands and feet, and almondshaped eyes. Approximately $70 \%$ of individuals with PWS have a 15q11.2-q13 deletion on the paternal chromosome 15, which is detectable by chromosome analysis, DNA methylation studies, or fluorescence in situ hybridization (FISH). Twenty-five percent have maternal uniparental disomy (UPD), or two copies of the maternal chromosome 15, with no paternal contribution. Less than $5 \%$ have an imprinting mutation. Both UPD and imprinting mutations are detectable by DNA methylation studies. Less than $1 \%$ of patients have a structural chromosome rearrangement involving 15q11.2-q13, which is detectable by chromosome analysis. ${ }^{1-3}$

Angelman syndrome (AS) is characterized by severe mental retardation with absent speech, microcephaly, inappropriate laughter, seizures, and a stiff, ataxic gait. Approximately $70 \%$ of individuals with AS have a 15q11.2-q13 deletion of the maternal chromosome, which is detectable by chromosome analysis, DNA methylation studies, or FISH. Eleven percent have a mutation in the E6AP ubiquitin protein ligase 3A (UBE3A) gene, which is detectable by DNA sequence analysis. Approximately $7 \%$ of AS patients have paternal UPD, and $3 \%$ have an imprinting mutation. Both UPD and imprinting mutations are

From the Department of Medical Genetics, Henry Ford Hospital, Detroit, Michigan.

Kristin G. Monaghan, PhD, Department of Medical Genetics, Henry Ford Hospital, 2799 West Grand Boulevard; CFP-4, Detroit, MI 48202.

Received: May 8, 2002.

Accepted: August 6, 2002.

DOI: 10.1097/01.GIM.0000035619.13886.AE detectable by DNA methylation studies. Less than $1 \%$ of AS patients have a structural chromosome rearrangement, which is detectable by chromosome analysis. In approximately $10 \%$ of AS patients, the molecular mechanism is not known. ${ }^{1-4}$

In 1996, the American Society of Human Genetics/American College of Medical Genetics Test and Technology Transfer Committee described two different approaches to the molecular diagnosis of PWS and AS. They recommended an approach based on a number of factors, including the local availability of testing, previous results for specific patients, and the level of diagnostic expertise of the ordering physician. ${ }^{5}$ With the rising cost of medical care and the need to manage cost in all areas of health care, we previously proposed that cost also be considered a factor. ${ }^{6}$

We considered three approaches for the molecular diagnostic testing of these syndromes. A chromosome analysis is performed for all three approaches to identify other chromosome abnormalities as recommended by the $\mathrm{ACMG}^{7,8}$ for all individuals with mental retardation or birth defects of unknown etiology. Approach IA is the same as approach I described by the ASHG/ACMG and begins with DNA methylation studies (Fig. 1). If methylation studies are positive, then the diagnosis of PWS or AS can be made, and FISH can then be used to determine if a deletion is present. A parental chromosome analysis is obtained if a 15q11.2-q13 deletion is detected by FISH to identify any inherited chromosome abnormalities. If FISH studies are normal, then UPD studies done by microsatellite analysis can be performed to differentiate between UPD and imprinting mutations. Normal methylation results essentially rule out PWS and 75 to $80 \%$ of AS. If the diagnosis of AS is still being considered after negative methylation studies, then UBE3A sequencing studies can be performed. 


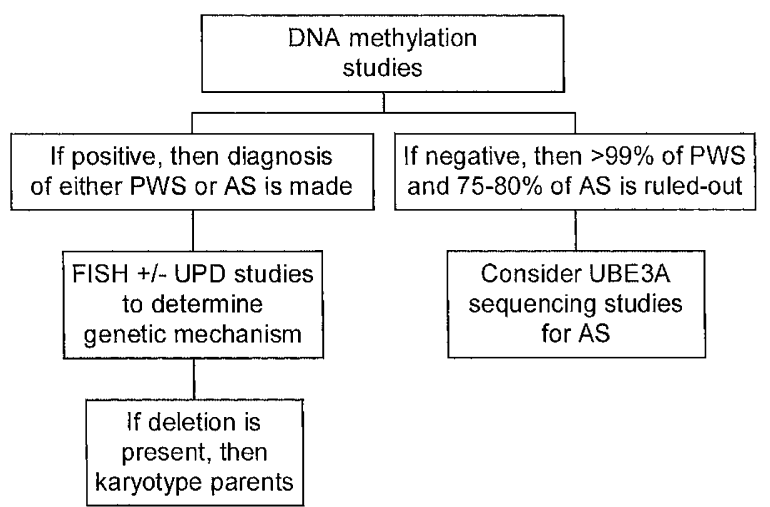

Fig. 1 Approach IA.

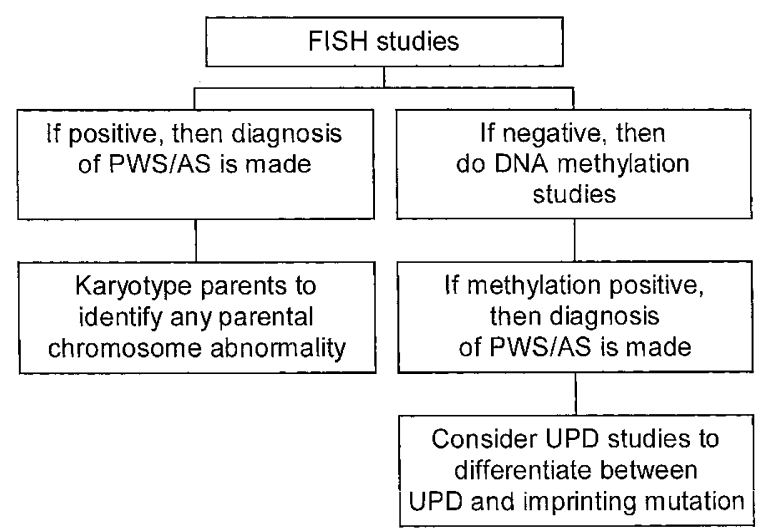

Fig. 2 Approach IB.

The second approach, IB, is an alternative approach to IA and begins with FISH studies (Fig. 2). A 15q11.2-q13 deletion detected by FISH confirms the diagnosis of PWS or AS. Parental chromosome analysis can then be obtained as previously described. Negative FISH results are followed by DNA methylation studies. Positive methylation results confirm a diagnosis of PWS or AS, depending on which parental allele is missing, and should be followed by microsatellite analysis to differentiate between UPD and imprinting mutations.

The third strategy is approach II as described by the ASHG/ ACMG. FISH and methylation studies are performed simultaneously in approach II (Fig. 3). Normal methylation and FISH results rule out PWS and 75 to $80 \%$ of AS. Again, UBE3A sequencing analysis can be done if the diagnosis of AS is still being considered. Positive FISH and DNA methylation studies confirm the diagnosis of PWS or AS. Positive FISH results should be followed by parental chromosome analysis to rule out inherited rearrangements. Abnormal methylation with normal FISH results should be followed by microsatellite analysis to distinguish between UPD and imprinting mutations.

We previously calculated the charges of laboratory testing for the three approaches based on varying percentages of referred patients actually being affected with PWS or AS, using charges of $\$ 200$ for FISH and $\$ 300$ for DNA methylation studies. ${ }^{6}$ The cost of chromosome analysis was not factored in because chromosome studies were performed on all patients and therefore did not affect the results. This showed that sequential testing, in other words either approach IA or IB, reduces patient costs. When the likelihood that a patient will test positive for PWS or AS is below 50\%, approach IA is less expensive than approach IB or approach II. This is because negative methylation results rule out PWS and most cases of AS, thereby eliminating the need for further laboratory testing. At our institution, $7.8 \%$ of specimens sent for DNA methylation studies for PWS are positive, and $19.6 \%$ of specimens sent for AS are positive. On the basis of these data, it appeared that approach IA would be the most cost-effective approach for our institution.

\section{METHODS}

Between July 1998 and March 2002, we used approach IA for most specimens received. A heparinized blood sample was used for cytogenetic studies and an ethylenediaminetetraacetate (EDTA) sample was used for DNA studies. DNA studies for PWS/AS were performed by restriction digest with $\mathrm{Xba \textrm {I }}$ and NotI, followed by Southern blot analysis using the small nuclear ribonucleoprotein $\mathrm{N}$ (SNRPN) probe. If no EDTA sample was received, then the heparinized specimen was shared between the DNA and cytogenetics laboratories. We used approach II when a specimen was received from a hypotonic newborn because concurrent FISH and DNA studies result in a faster turn-around time, which may make a difference in how some patients are managed.

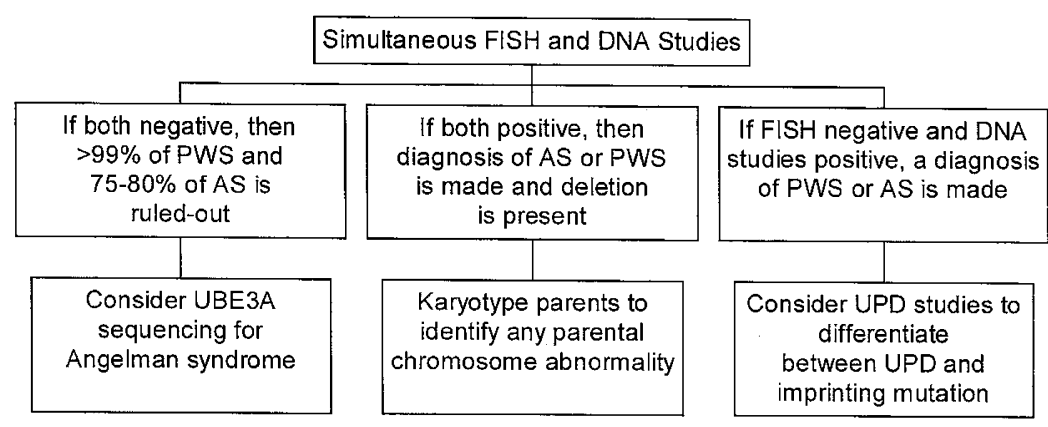

Fig. 3 Approach II. 
Table 1

Cases with an abnormal karyotype, but not del(15q11.2-q13), and normal methylation studies

\begin{tabular}{l}
\hline Karyotype \\
\hline $46, \mathrm{XY}, \mathrm{t}(15 ; 18)(\mathrm{q} 26.1 ; \mathrm{q} 12.2)$ \\
47,XY,+dic(15).ish idic(15)(q11)(D15Z1++,SNRPN-) \\
46,XY,add(16)(q21) \\
46,XY,t(7;15)(q22;q15) \\
47,XX,+21 \\
46,XX,der(8)t(4;8)(p15;p23.1) \\
46,XY,dup(15)(q11.2q11.2)
\end{tabular}

Table 2

Summary of cases positive for PWS/AS

\begin{tabular}{|c|c|c|c|}
\hline $\begin{array}{l}\text { Prader-Willi } \\
\text { syndrome }\end{array}$ & Mechanism & $\begin{array}{l}\text { Angelman } \\
\text { syndrome }\end{array}$ & Mechanism \\
\hline $\begin{array}{l}\text { One del(15), } \\
\text { positive FISH } \\
\text { and DNA } \\
\text { studies }\end{array}$ & Deletion & $\begin{array}{l}\text { Two del(15), } \\
\text { positive FISH } \\
\text { and DNA } \\
\text { studies }\end{array}$ & Deletion \\
\hline $\begin{array}{l}\text { One normal } \\
\text { chromosome } \\
\text { analysis, } \\
\text { normal FISH, } \\
\text { and positive } \\
\text { DNA studies }\end{array}$ & $\begin{array}{l}\text { Maternal uniparental } \\
\text { disomy }\end{array}$ & $\begin{array}{l}\text { Four normal } \\
\text { chromosome } \\
\text { analysis, } \\
\text { positive FISH } \\
\text { and DNA } \\
\text { studies }\end{array}$ & Deletion \\
\hline $\begin{array}{l}\text { One der(6;15)t } \\
(6 ; 15) \text { mat, } \\
\text { negative FISH, } \\
\text { and positive } \\
\text { DNA studies }\end{array}$ & $\begin{array}{l}\text { Structural chromosome } \\
\text { rearrangement }\end{array}$ & & \\
\hline
\end{tabular}

\section{RESULTS}

We received 136 specimens for chromosome analysis and DNA methylation analyses for PWS or AS. Of the 136 cases, 114 had a normal chromosome analysis and methylation studies. Nine patients were positive for AS and three were positive for PWS. Seven patients had an abnormal chromosome analysis, but not deletion 15q11.2-q13, and normal methylation studies (Table 1).

Of the patients with PWS, one had a 15q11.2-q13 deletion detected by chromosome analysis and FISH. DNA methylation studies were positive for PWS. One patient had UPD with normal chromosome analysis and normal FISH and positive DNA methylation studies. The third patient had a maternally inherited translocation, $\mathrm{t}(6 ; 15)(\mathrm{p} 25 ; \mathrm{q} 11)$, and normal FISH (because the breakpoint was distal to the SNRPN probe critical region) and positive DNA methylation studies (Table 2).

Of the nine patients with AS, four had a deletion detected by chromosome analysis and FISH. These patients also had positive DNA methylation studies. Five patients had a normal chromosome analysis, with a deletion detected by FISH and positive DNA methylation studies (Table 2).

Of the 136 specimens received, 35 (25.7\%) were submitted with heparinized blood only. We obtained DNA methylation results in 34 of 35 (97\%) of these cases. Failure to extract DNA from a heparin sample occurred only once, and the cytogenetic studies were normal.

On the basis of our actual results, we compared the cost of each strategy, assuming $\$ 200$ for FISH and $\$ 300$ for DNA testing. Because a chromosome analysis was done in every case, that cost was not considered. The overall cost to the patients for approach IA (methylation studies followed by FISH for only methylation positive patients) would have been $\$ 42,200$. The cost for IB (FISH followed by methylation for all FISH negative patients) would have been $\$ 65,000$, and the cost for approach II (simultaneous methylation and FISH studies) would have been $\$ 68,000$. The cost savings between approach IA and IB would have been $\$ 22,800$, or $\$ 167.65$ per patient. The cost savings would have been $\$ 25,800$, or $\$ 189.71$ per patient, between approach IA and approach II.

\section{DISCUSSION}

We have adopted approach IA at our institution. However, for hypotonic infants, where reporting time is critical, we use approach II and perform FISH and DNA testing simultaneously. We feel that in some situations it is important to forgo patient cost to expedite a diagnosis. We request a heparinized blood sample for chromosome analysis and FISH analysis and an EDTA sample for DNA testing. If an EDTA specimen is not received, then the heparinized sample is shared between the DNA and cytogenetic laboratories. Our experience has confirmed that approach IA, DNA methylation studies followed by FISH, is cost effective and clinically appropriate.

\section{References}

1. Cassidy SB. Prader-Willi syndrome. J Med Genet 1997;34:917-923.

2. Mann MR, Bartolomei MS. Towards a molecular understanding of Prader-Willi and Angelman syndromes. Human Molecular Genetics 1999;8:1867-1873.

3. Gene Clinics web site, 2002; http://www.geneclinics.org/html.

4. Jiang Y, Lev-Lehman E, Bressler J, Tsai T-F, Beaudet L. Genetics of Angelman syndrome. Am J Hum Genet 1999;65:1-6.

5. ASHG/ACMG (American Society of Human Genetics/American College of Medical Genetics Test, and Technology Transfer Committee). Diagnostic testing for PraderWilli and Angelman syndromes: report of the ASHG/ACMG Test and Technology Transfer Committee. Am J Hum Genet 1996;58:1085-1088.

6. Monaghan KG, Van Dyke DL, Feldman G, Wiktor A, Weiss L. Diagnostic testing: a cost analysis for Prader-Willi and Angelman syndromes. Am J Hum Genet 1997;60: 244-247.

7. Curry CJ, Stevenson RE, Aughton D, Byrne J, Carey JC, Cassidy S, Cunniff C, Graham JM, Jones MC, Kaback MM, Moeschler J, Schaefer GB, Schwartz S, Tarleton J, Opitz $\mathrm{J}$, of the American College of Medical Genetics. Evaluation of mental retardation: recommendations of a consensus conference. Am J Med Genet 1997;72:468-477.

8. American College of Medical Genetics Foundation, and New York State Department of Health web site. Evaluation of the newborn with single or multiple congenital anomalies: a clinical guideline, 2002; http://www.health.state.ny.us/nysdoh/dpprd/ main.html. 